\title{
O ensino da Ética em Administração: PercepÇões e OPINIÕES DOS ALUNOS
}

THE TEACHING OF ETHICS IN ADMINISTRATION: STUDENTS' PERCEPTIONS AND OPINIONS

\section{DANIELA Abrantes FerReIRA (dabrantes@uol.com.br)}

UNIVERSIDADE FEDERAL DO RIO DE JANEIRO

\section{LUCELENA FERREIRA}

IBMEC-RIO DE JANEIRO

\section{MARINA DiAS DE FARIA}

UNIVERSIDADE FEDERAL DO RIO DE JANEIRO

\section{RESUMO}

O objetivo deste trabalho é o de ampliar o entendimento sobre as percepções e opiniões dos alunos a respeito do ensino da Ética nas escolas de Administração. Com base em estudo junto a um grupo de alunos de curso de graduação em Administração de uma faculdade privada do Rio de Janeiro, buscou-se investigar: qual a concepção dos alunos sobre o termo Ética; qual a importância que eles atribuem ao estudo da Ética e como deve ser o ensino da Ética nas escolas de Administração. A revisão bibliográfica trata da definição deste constructo e das contribuições de estudos sobre o ensino da Ética em Administração. Para se atingir o objetivo proposto, utilizou-se uma abordagem qualitativa, por meio de sete grupos focais, totalizando 74 participantes. Os resultados evidenciaram a importância que os alunos conferem ao ensino da Ética na faculdade de Administração, a ênfase em métodos de ensino participativo em um ambiente favorável bem como as críticas ao enfoque dado pela faculdade ao ensino da Ética. As conclusões apontam caminhos para o ensino de Ética nas faculdades de Administração.

Palavras-chave: Ética; graduação em Administração; métodos de ensino. 


\section{ABSTRACT}

The objective of this research project is to expand the understanding of the perceptions and opinions of students regarding the teaching of ethics in administration schools. Based on a study performed with a group of students of a Business Administration undergraduate course, from a private school in Rio de Janeiro, this project aimed to investigate the students' conception about the term Ethics, the importance they attach to the study of ethics and how the teaching of ethics should be carried out in business administration schools. The review deals with the definition of this construct and contributions of studies on the teaching of Ethics in administration. In order to achieve the proposed objective, it was used a qualitative approach, through seven focus groups, totaling 74 participants. The results showed the importance that students attach to the teaching of Ethics in the faculty of Business Administration, the emphasis on participatory teaching methods in an auspicious environment, and criticism to the approach taken by the faculty towards the teaching of Ethics. The conclusions point different paths for the teaching of Ethics within Business Administration faculties.

Keywords: Ethics; business Administration undergraduate courses; teaching methods.

\section{INTRODUÇÃO}

As escolas de Administração têm como missão preparar seus alunos para serem gestores eficientes em diversos tipos de negócios. Em geral, as decisões envolvem uma dimensão Ética e, portanto, pode-se considerá-la como parte integrante do processo decisório de um gestor de organizações. Neste sentido, as escolas de Administração - de graduação e pós-graduação - têm a responsabilidade de levar seus alunos a refletir sobre possíveis desafios éticos que enfrentarão em suas vidas profissionais (FELTON; SIMS, 2005).

O ensino da Ética é um desafio para professores de Administração. Com os recentes escândalos no mundo organizacional, a importância do ensino da Ética nos cursos de Administração provocou debates significativos no meio acadêmico (FARIA; CARVALHO, 2008; LADITKA; HOUCK, 2006; FELTON; SIMS, 2005; ADKINS; RADTKE, 2004). Os professores enfrentam dúvidas sobre sua capacidade 
de preparar administradores para gerir organizações de forma responsável e ética (FELTON; SIMS, 2005). Embora haja um número considerável de estudos a respeito do tema (GAUTSCHI; JONES, 1998; MURPHY; BOATRIGHT, 1994; BURTON; JOHNSTON; WILSON, 1991; ICHIKAWA, 2006), ainda não há consenso sobre a efetividade do ensino de Ética em faculdade de Administração (ADKINS; RADTKE, 2004). Muitos estudos focaram a percepção dos alunos de Administração a respeito da Ética (SERPA, 2005; COLE; SMITH, 1995; DUIZEND; MCCANN, 1998), mas parece não haver um estudo que tenha investigado a percepção dos alunos sobre o ensino desta temática nos cursos de Administração (ADKINS; RADTKE, 2004).

Alguns autores chamaram a atenção para o papel limitado do ensino da Ética em instituições de ensino (LADITKA; HOUCK, 2006), enquanto outros se preocuparam em definir qual seria a melhor forma de tratar este tema junto aos alunos de Administração, buscando sugerir metodologias mais adequadas para este fim (McDONALD; DONLEAVY, 1995; BURTON; JOHNSTON; WILSON, 1991). Entretanto, como os próprios alunos gostariam que o tema fosse tratado nas escolas de Administração? O objetivo deste trabalho é ouvir a opinião dos alunos, buscando ampliar o entendimento deles sobre as percepções e opiniões a respeito do ensino da Ética nas escolas de Administração. Baseados em estudo junto a um grupo de alunos de um curso de graduação em Administração, de uma faculdade privada, da cidade do Rio de Janeiro, buscou-se investigar: qual a concepção que os alunos têm sobre o termo Ética; qual a importância que eles atribuem ao estudo da Ética; e como deve ser o ensino da Ética nas escolas de Administração. As respostas a estas perguntas visam a ampliar o entendimento de pesquisadores e professores sobre como desempenhar seu papel na formação de administradores éticos e conscientes de seus atos e do impacto destes na sociedade.

\section{FUNDAMENTAÇ̃̃o TEÓRICA}

Ética vem do grego ethos, que significa costume, modo de agir (PASSOS, 2004). Ética é a parte da filosofia que estuda a moralidade dos atos humanos, com ênfase na determinação do que seria certo ou errado (ARRUDA, 2005). Desde os seus primórdios, o conceito de Ética está relacionado à ideia de altruísmo, isto é, considerar o bem-estar do outro ao tomar suas decisões. Srour (2003) classifica como free riders aquelas 
pessoas que agem em benefício próprio, prejudicando o bem comum, e que conseguem maximizar suas vantagens pessoais à custa do comportamento ético da maioria.

No contexto brasileiro, DaMatta (2000) considera que a hibridez cultural faz com que o Brasil conviva por um lado com princípios éticos de integridade, imparcialidade, altruísmo e, por outro, com o oportunismo, o jeitinho como modo de navegação social, a tendência de se levar vantagens nas situações, atendendo a interesses individuais. A cultura brasileira abriga, portanto, uma duplicidade de morais. Convivem, lado a lado, a moral da integridade e a moral do oportunismo (BARBOSA, 1999). Esta duplicidade influencia indivíduos e organizações (SROUR, 2003).

Por que razão se estuda Ética em faculdades de Administração? As decisões organizacionais e seus resultados alcançam um universo de agentes sociais muito mais amplo do que aquele composto pelos sócios e acionistas das empresas, que afetam seu ambiente interno e externo (BORGER, 2001; CHERMAN; TOMEI, 2005; CAMPOS, 2006). Os gestores organizacionais, especialmente aqueles que ocupam lugares de intervenção estratégica, estão frequentemente expostos a pressões Éticas (ALMEIDA, 2007). Segundo Srour (2003, p. 50), "as decisões empresariais não são inócuas, anódinas ou isentas de consequências: carregam um enorme poder de irradiação pelos efeitos que provocam". A favor desta visão, Carroll (1999) argumenta que a responsabilidade Ética da organização deriva justamente de seu grande poder social, considerando que suas decisões, por terem amplas consequências para a sociedade, não podem ser tomadas unicamente motivadas por fatores econômicos. Alinhados à ideia de Mohr, Webb e Harris (2001), defendem que a responsabilidade Ética das organizações passa pelo compromisso de minimizar ou eliminar os efeitos negativos das ações organizacionais e maximizar os benefícios de longo prazo dessas ações para a sociedade.

Destas concepções deriva o conceito de Ética organizacional, que compreende princípios e padrões que orientam o comportamento no mundo dos negócios (FERRELL; FRAEDRICH; FERRELL, 2001; VALLS, 1994). Neste sentido, as responsabilidades éticas correspondem aos comportamentos esperados pela sociedade, apesar de não codificados por lei, que envolvem uma série de normas, padrões e expectativas para atender o que os diversos públicos da organização consideram como legítimos, corretos e justos (ASHLEY et al., 2005). 


\section{O Ensino da Ética em Faculdades de Administração}

O interesse acadêmico pela Ética tem pelo menos 2.300 anos. Platão e Aristóteles já estudavam questões sobre o certo e o errado, no período clássico de Atenas. Na filosofia oriental, estas questões também já figuram há muitas centenas de anos (FELTON; SIMS, 2005). No século XX, o ensino da Ética foi introduzido de forma pioneira na Harvard Business School, em 1908 (BARROS; PASSOS, 2000). Mas, foi nas décadas de 1960 e 1970 que o ensino deste tema em faculdades de Administração e escolas de negócios tomou impulso, principalmente nos Estados Unidos, aonde alguns filósofos foram levar sua contribuição. Estes filósofos, ao complementarem sua formação acadêmica com a vivência empresarial, aplicando os conceitos de Ética à realidade dos negócios, iniciaram a discussão sobre uma nova dimensão, a Ética organizacional (ARRUDA, 2005).

A década de 1980 caracterizou-se por esforços isolados de professores e universidades que, sobretudo nos Estados Unidos e Europa, se dedicaram ao ensino da Ética organizacional (ARRUDA, 2005). Surgiram nesta década publicações sobre o tema, incluindo a criação do primeiro periódico específico sobre Ética na área de Administração: Journal of Business Ethics. Na década de 1990 foram lançadas outras publicações importantes, tais como Business Ethics Quartely e Business Ethics: An European Review.

A última década do século passado foi marcada por diversos escândalos corporativos que envolviam empresas como Enron, WorldCom Inc., Arthur Andersen e DASLU, que vieram ampliar a discussão em torno da Ética organizacional (FARIA; CARVALHO, 2008; LADITKA; HOUCK, 2006; FELTON; SIMS, 2005; ADKINS; RADTKE, 2004). No Brasil, observa-se um declínio da credibilidade das instituições, sobretudo das grandes empresas (INSTITUTO ETHOS, 2004; SERPA; FOURNEAU, 2004). Uma pesquisa abrangendo diversas cidades brasileiras, realizada pelo Instituto Ethos (entidade sem fins lucrativos, que reúne empresas interessadas em responsabilidade social), indicou que $41 \%$ das pessoas têm pouca ou nenhuma confiança nas grandes empresas brasileiras e $60 \%$ das pessoas demonstram esta mesma falta de confiança em relação às empresas multinacionais que atuam no Brasil. Neste contexto, o papel das instituições de ensino vem sendo questionado no que se refere à formação de alunos com maior consciência Ética de seus atos e dos impactos de suas decisões para a sociedade. 
A maior parte dos estudos sobre o ensino da Ética nas escolas de Administração tem se preocupado em investigar sua eficácia na mudança de atitude dos alunos frente a situações que envolvem questões Éticas. Nesses estudos foram exploradas formas de manifestação da Ética nas organizações como declaração de valores organizacionais, código de Ética ou de conduta e planos de Responsabilidade Social Empresarial. O Quadro 1 apresenta um resumo dos resultados de estudos seminais sobre o assunto. Existem estudos relevantes mais recentes sobre o tema, mas esses foram escolhidos por terem sido a base para os mais recentes.

Quadro 1: Pesquisas sobre a Eficácia do Ensino da Ética

\begin{tabular}{|c|c|c|}
\hline Autor/ano & Método & Público \\
\hline $\begin{array}{c}\text { Gautschi e } \\
\text { Jones (1998) }\end{array}$ & $\begin{array}{l}\text { Aplicação de questionários em um grupo controle } \\
\text { e um grupo experimental que havia participado } \\
\text { de um curso de Ética; Análise quantitativa dos } \\
\text { dados }\end{array}$ & $\begin{array}{l}\text { Alunos de } \\
\text { graduação }\end{array}$ \\
\hline $\begin{array}{l}\text { Murphy e } \\
\text { Boatright } \\
(1994)\end{array}$ & $\begin{array}{l}\text { Aplicação de questionários em um grupo controle } \\
\text { e um grupo experimental que havia participado } \\
\text { de um curso de Ética; Análise quantitativa dos } \\
\text { dados }\end{array}$ & $\begin{array}{l}\text { Alunos de } \\
\text { graduação }\end{array}$ \\
\hline $\begin{array}{l}\text { Burton, } \\
\text { Johnston e } \\
\text { Wilson (1991) }\end{array}$ & $\begin{array}{l}\text { Aplicação de questionários em um grupo controle } \\
\text { e dois grupos experimentais, um que havia } \\
\text { participado de uma palestra com discussão sobre } \\
\text { situações Éticas de negócio e uma palestra com } \\
\text { uma abordagem mais filosófica da Ética; Análise } \\
\text { quantitativa dos dados }\end{array}$ & $\begin{array}{l}\text { Alunos de } \\
\text { graduação }\end{array}$ \\
\hline $\begin{array}{c}\text { Wynd e Mager } \\
\text { (1989) }\end{array}$ & $\begin{array}{l}\text { Aplicação de questionários em um grupo controle } \\
\text { e um grupo experimental que havia participado } \\
\text { de um curso de Ética; Análise quantitativa dos } \\
\text { dados }\end{array}$ & $\begin{array}{l}\text { Alunos de } \\
\text { graduação }\end{array}$ \\
\hline $\begin{array}{l}\text { Stead e Miller } \\
\quad(1988)\end{array}$ & $\begin{array}{l}\text { Aplicação de questionários em uma mesma } \\
\text { amostra antes e depois do curso de Ética; } \\
\text { Análise quantitativa dos dados }\end{array}$ & $\begin{array}{c}\text { Alunos de } \\
\text { graduação e de } \\
\text { pós-graduação }\end{array}$ \\
\hline $\begin{array}{c}\text { Arlow e } \\
\text { Ulrich (1988) }\end{array}$ & $\begin{array}{l}\text { Aplicação de questionários em um grupo controle } \\
\text { e um grupo experimental, depois de exposto ao } \\
\text { curso de Ética. Aplicação do questionário em } \\
\text { parte da amostra do grupo experimental quatro } \\
\text { anos depois; Análise quantitativa dos dados }\end{array}$ & $\begin{array}{l}\text { Alunos de } \\
\text { graduação }\end{array}$ \\
\hline Martin (1981) & $\begin{array}{l}\text { Aplicação de questionários em um grupo controle } \\
\text { e um grupo experimental, depois de exposto ao } \\
\text { curso de Ética; } \\
\text { Análise quantitativa dos dados }\end{array}$ & $\begin{array}{l}\text { Alunos de } \\
\text { graduação }\end{array}$ \\
\hline Boyd (1981) & $\begin{array}{l}\text { Aplicação de questionários em uma mesma } \\
\text { amostra antes e depois do curso de Ética. Análise } \\
\text { quantitativa dos dados }\end{array}$ & $\begin{array}{l}\text { Alunos de } \\
\text { graduação }\end{array}$ \\
\hline
\end{tabular}


Wynd e Mager (1989) ressaltam a importância de se estudar a eficácia do ensino da Ética argumentando que, se não há mudanças na forma de o aluno pensar a Ética, então os recursos alocados para esta disciplina talvez devessem ser aplicados em outro lugar. Estes autores defendem que os critérios que as pessoas usam para julgar situações que envolvem dilemas éticos são formados ao longo da vida, por meio da influência da família, religião, educação e interação cultural, e, desta forma, um único curso de Ética na universidade não é capaz de modificar valores no indivíduo. Alinhados a esta ideia, Murphy e Boatright (1994) e Bunke (1988) argumentam que Ética não é algo que possa ser ensinado e que esta não seria melhor forma de uma instituição de ensino alocar seus recursos. Para Murphy e Boatright (1994), no entanto, estes críticos cometem um erro ao considerar que um curso sobre Ética deveria ter como objetivo modificar o comportamento dos alunos. Estes autores argumentam que se trata de um objetivo irrealista, na medida em que os alunos provavelmente já adquiriram seus códigos pessoais de conduta bem antes de entrar na faculdade. Entretanto, os autores afirmam que o ensino da Ética é relevante, e seus estudos apontaram que este pode fazer com que os alunos se tornem mais sensíveis às questões Éticas em sua vida profissional. Outros autores corroboraram estes resultados, indicando que aumentar a sensibilidade dos alunos a questões Éticas pode ser um objetivo viável para o ensino da Ética (GAUTSCHI; JONES, 1998).

O objetivo do ensino da Ética nas escolas de Administração também tem sido foco de reflexão para os autores. Sims e Sims (1991) sugerem que este ensino deve almejar três objetivos: melhorar a habilidade de reconhecer questões Éticas no ambiente de trabalho; melhorar a habilidade para fazer julgamentos morais; esclarecer suas aspirações morais. Para Barros e Passos (2000), todo o ensino de Administração precisa ser orientado por uma reflexão deontológica, que permita ao futuro administrador ser capaz de exercer suas atividades profissionais com responsabilidade social. Já, para Schwartz, Kassem e Ludwig (1991), o objetivo do ensino da Ética na faculdade de Administração deveria ser o de ajudar o estudante a conseguir uma congruência entre fazer o que é certo e fazer o que é preciso para ter sucesso na carreira.

Para Weber (1990), é preciso achar a metodologia mais adequada para que o ensino da Ética tenha algum feito na atitude dos alunos. Este autor diferencia três abordagens de ensino: filosófica-normativa, baseada em exposições sobre a Ética na filosofia; descritiva, tendo como base para discussões em aula materiais sobre atualidades e estudos de caso; 
analítica-gerencial, que usa bibliografia em Administração, pesquisas, reportagens sobre práticas de negócios e estudos de caso.

Outros autores buscaram testar qual seria a metodologia mais adequada a se usar. Burton, Johnston e Wilson (1991), por exemplo, realizaram um estudo que testou a eficácia de dois diferentes métodos de ensino de Ética: uso de cenários contendo situações reais de negócio e uma abordagem mais filosófica. O estudo contou com 783 alunos na amostra, divididos em três grupos: um exposto a uma aula com uso dos cenários, outro exposto a uma aula com abordagem filosófica e outro grupo que não foi exposto a nenhuma aula sobre o tema (controle). Os resultados indicaram que o método que utilizou as discussões sobre cenários apresentou vantagens sobre o método de abordagem filosófica, no que se refere ao impacto na atitude dos alunos.

Sims (2002) considera que o ambiente de sala de aula é um fator importante e deve ser desenhado para abrigar discussões e conflitos a respeito do tema. Segundo este autor, é fundamental um ambiente que proporcione segurança para que os alunos possam dividir suas opiniões e valores relacionados à Ética. Neste sentido, o papel do professor é relevante e ele é quem deve enfatizar a importância do respeito às divergências de opiniões e valores. Este ambiente promove a oportunidade para que os alunos aprendam não só com o professor, mas também ouvindo as diferentes opiniões de seus colegas (LADITKA; HOUCK, 2006).

Felton e Sims (2005) argumentam que, para que isto aconteça, é necessário que os alunos compreendam seus próprios valores, as mudanças dos cenários nos quais estarão tomando suas decisões, os conflitos frequentes de interesses entre os diferentes públicos das empresas e o impacto que suas ações como gestores terão na sociedade. Para estes autores, é desta forma que os alunos irão desenvolver uma sensibilidade Ética para seu trabalho. Os autores fazem uma recomendação específica, sugerindo que os alunos sejam estimulados a escrever, individualmente, sobre experiências envolvendo dilemas éticos, além do uso de estudos de casos. Corroborando as recomendações de Felton e Sims (2005), outros autores sugerem que o foco do ensino da Ética deve estar em aumentar a consciência dos alunos sobre seus valores e suas atitudes perante as situações éticas (BRINKMANN; SIMS, 2001; SIMS; SIMS, 1991).

Diversos autores apontam que a aprendizagem participativa, que envolve atividades vivenciais, como estudos de casos, seria a melhor forma de se conseguir sucesso no ensino da Ética (BRINKMANN; SIMS, 
2001; SANYAL, 2000; SIMS, 2002). Para estes autores, esta metodologia de ensino possibilitaria que os alunos entendessem as situações éticas, tais como estas podem ser encontradas na vida profissional. Laditka e Houck (2006) enfatizam que a chave para o sucesso do ensino da Ética é tornar o tema relevante para os alunos. Murphy e Boatright (1994) reforçam a importância de se definir como deve ser o ensino da Ética, afirmando que as pesquisas sobre o tema deveriam ajudar a definir questões cruciais sobre o que incluir na disciplina, onde posicioná-la no currículo do curso, e quais os melhores métodos a serem empregados.

O presente trabalho propõe que uma forma profícua de avaliar as contribuições da teoria sobre o ensino da Ética, problematizando as lacunas que ainda existem, ou corroborando os resultados e recomendações encontrados, é ampliando o entendimento sobre a percepção dos alunos a respeito do tema.

\section{Metodologia}

A escolha da metodologia deste estudo pautou-se pelo interesse em explorar as percepções e opiniões dos alunos de Administração sobre o ensino da Ética. Por se tratar de um tema ainda pouco estudado, sobretudo no universo brasileiro, a metodologia qualitativa, com uso de grupo focal, mostra-se coerente com os objetivos pretendidos. Para Morgan (1993), trata-se de um método adequado a estudos exploratórios sobre percepções e opiniões das pessoas, bastante disseminado entre as ciências sociais.

Participaram da pesquisa 74 alunos do curso de Administração de uma faculdade privada da cidade do Rio de Janeiro, do primeiro ao sétimo período, com idades entre 17 a 22 anos, moradores de bairros de classe média e média alta desta cidade. A pesquisa foi realizada no início do primeiro semestre de 2009. A escolha da faculdade e dos alunos deu-se por conveniência (VERGARA, 2009). A faculdade na qual foi realizado o estudo está no mercado há quase 50 anos e possui poucos cursos, mas o curso de Administração é muito tradicional. Os alunos dessa faculdade cursam a disciplina "liderança e Ética" somente no sexto período.

Foram realizados sete grupos focais, com a participação de no mínimo 10 e no máximo 12 integrantes por grupo. As discussões foram gravadas com a autorização dos participantes e a duração foi de aproximadamente 40 minutos por grupo. Observando-se o contexto em que os grupos focais foram realizados, entende-se que os alunos puderam se expressar livremente. Gatti (2005) ressalta que interações 
ocorridas em ambiente no qual os participantes são colegas reforça a segurança para se expressarem com maior liberdade.

Foram usadas questões semiestruturadas, permitindo mais flexibilidade. As moderadoras se preocuparam em manter a discussão do grupo focada nos tópicos relevantes para a pesquisa, permitindo que todos pudessem se expressar e evitando reter o fluxo das discussões.

Para definição de quantos grupos incluir na pesquisa, foi seguida a recomendação de Krueger (2000), segundo a qual quando o moderador puder prever o que será dito no próximo grupo, então deverá dar por concluído o estudo. No que se refere à quantidade de participantes por grupo, foi seguida a recomendação de Gatti (2005), que sugere entre seis e 12 pessoas. Krueger (2000) reforça a importância de se ter um número adequado de participantes por grupo, ponderando que este número deve ser pequeno o suficiente para que todos tenham a oportunidade de se expressar no grupo, e grande o suficiente para proporcionar diversidade de opiniões.

Para guiar o tratamento do material coletado nas entrevistas, foi utilizada a análise hermenêutica. Para Minayo (2004), a hermenêutica é a busca de compreensão de sentido que se dá na comunicação entre as pessoas, cujo núcleo central é a linguagem. Por meio da interpretação da linguagem, pode-se compreender representações e contextos culturais relacionados à localização histórica e social do emissor da mensagem. Cumpre ressaltar que qualquer interpretação produzida, segundo a proposta hermenêutica, liga-se inexoravelmente ao viés histórico e social do próprio pesquisador.

De acordo com Thompson (1997), a interpretação hermenêutica de dados textuais se dá por meio de uma série de interações entre a parte e o todo, valorizando as próprias palavras dos entrevistados. Segundo o autor, este processo interativo envolve dois estágios distintos. $\mathrm{O}$ primeiro é um ciclo intratexto no qual um texto é lido em sua totalidade para ganhar um sentido de todo. Leituras adicionais são empreendidas para desenvolver uma compreensão dos significados presentes no texto. $O$ segundo movimento é da parte para o todo, intertextual, no qual padrões e diferenças entre as entrevistas são procurados. Também há movimentos interativos entre os ciclos intra e intertextuais. Gatti (2005) destaca a importância de se focar a análise das informações oriundas de grupos focais na interação entre os sujeitos pesquisados, destacando consensos, dissensos, rupturas, opiniões majoritárias, bem como aquelas que ficaram em minoria. A autora argumenta que “(...) tendo sido as interações em 
grupo a justificativa maior para utilizar o grupo focal como técnica de pesquisa, elas devem merecer um olhar especial"' (GATTI, 2005, p.47).

Algumas limitações desta pesquisa estudo merecem consideração. Uma das mais relevantes é que o assunto pesquisado - Ética - dá margem à ocorrência do chamado viés da desejabilidade social (ERFFMEYER; KELLOR; LECLAIR, 1999; GAVA; SILVEIRA, 2007). Este viés ocorre quando os participantes da pesquisa baseiam suas respostas no que percebem como uma resposta socialmente valorizada. A atuação do mediador dos grupos buscou minimizar a ocorrência deste viés, incentivando os participantes a dar as informações mais genuínas sobre suas próprias percepções, ressaltando a importância desta atitude para a legitimidade da pesquisa e pontuando que o estudo não tem a intenção de julgamento de valor das opiniões dos sujeitos pesquisados. Além disso, a dinâmica interativa que ocorre nos grupos focais pode favorecer o aumento da espontaneidade nas colocações, já que há múltiplos interlocutores, colegas de turma, ficando a presença do mediador menos evidente. Nos grupos, os participantes se questionam mutuamente, e as reações a estes questionamentos normalmente são imediatas e enfáticas, podendo neutralizar a intenção de se colocar de uma forma previamente arranjada, com base no que se considera socialmente mais adequado. Em uma entrevista em profundidade, por exemplo, onde o entrevistado fica face a face com o entrevistador, pode-se supor que este viés apareça com maior intensidade.

Outra limitação importante diz respeito aos grupos pesquisados, formados por alunos de uma faculdade privada da cidade do Rio de Janeiro, pertencentes à classe média e média alta. Este fato pode criar viéses nas respostas, os quais estão fora do controle da pesquisa, e devem ser levados em conta na interpretação dos resultados obtidos. Considerando que a pesquisa qualitativa não busca a generalização estatística de seus resultados, vale ressaltar que as informações geradas pelos participantes devem servir para um início de reflexão sobre o ensino da Ética em escolas de Administração. Em que pesem as limitações aqui expostas, a escolha da metodologia justifica-se pelo fato de possibilitar a geração de uma riqueza de conteúdo que poderá suscitar diversas indagações para pesquisas futuras. 


\section{ANÁLISE DOS RESULTADOS}

Tomando como base os objetivos da pesquisa, nos grupos focais realizados foram explorados três pontos centrais: a concepção de Ética para os alunos; a importância do estudo da Ética; como os alunos julgam que deveria ser o ensino da Ética nas escolas de Administração. A análise dos resultados exposta a seguir está baseada nestes três aspectos.

Buscou-se observar se existiam diferenças nas respostas dos alunos dependendo do sexo e do período em que eles estavam. Não foram encontradas diferenças.

\section{Conceito de Ética}

No discurso de todos os grupos pesquisados observa-se que a concepção de Ética está relacionada com a definição do que é certo e errado. Há um consenso de que se trata de um conceito que extrapola o âmbito pessoal, individual, e está inserido num contexto social, com várias interpretações, dependendo do grupo e do lugar onde se esteja.

Um ponto de concordância é a crença de que a Ética promove harmonia, entrelaçando o individual e o social, como atesta o depoimento de alguns alunos: "A Ética ajuda a viver em sociedade"; "A Ética ajuda a manter o equilíbrio entre o individual e o coletivo".

Observou-se uma relativização das noções de certo e errado: o que é ético para um grupo não é necessariamente para outro. Aqui aparece a importância das instituições (família, escola, igreja, empresa) para fornecer parâmetros. Entre as instituições citadas, família e escola (educação infantil) adquirem maior relevância para os grupos estudados.

Apesar do foco na infância, como período determinante para o aprendizado da Ética, aparece com frequência a ideia de que a formação Ética é um processo sem fim, que ocorre ao longo da vida: "É um joguinho de lego que você vai construindo"; "Os valores você vai adquirindo com a idade, com as influências que recebe". Segundo os alunos, este aprendizado "vai sendo construindo ao longo do tempo", sob a influência de diversos ambientes e agentes sociais. O papel da família aparece sempre como muito importante neste percurso: "Tudo começa pelo exemplo: se você não tem um bom exemplo em casa, não vai ter valores éticos"; "Os jovens se miram muito nos pais, mesmo sem admitir"; "Acho que pai e mãe têm que dar o exemplo". Vale ressaltar que alguns alunos, que já trabalham, destacaram o fato, atualmente, o ambiente de trabalho exercer forte e positiva influência sobre sua 
formação Ética, pois as empresas em que trabalham valorizam e exercitam a Ética. Estas considerações remetem ao fato de as empresas estarem, atualmente, enfatizando a importância do comportamento ético de seus colaboradores (LADITKA; HOUCK, 2006; FELTON; SIMS, 2005; ADKINS; RADTKE, 2004).

Pôde-se observar entre os alunos facilidade em definir Ética quando esta está relacionada a grandes dilemas, e alguma dificuldade em defini-la no contexto dos pequenos dilemas do dia-a-dia: "Os políticos brasileiros não são éticos"; "Para administrar o Brasil tem que ser ético"; "Um pequeno empresário que não dá nota fiscal... não sei se isto seria uma falta de Ética"; "Diante dos problemas tão graves de Ética no Brasil, a gente não pode considerar que avançar o sinal seja uma falta de Ética".

Diversos alunos (e aqui não houve consenso, mas sim recorrência) afirmaram que realizam ações contrárias à Ética no seu dia-a-dia, deslocando o foco para o benefício individual. A frase seguinte, dita por uma aluna, reforça esta ideia: "Dependendo dos resultados que se quer alcançar, talvez valha à pena [agir de forma antiética]". Ficou claro o efeito devastador que o comportamento de algumas figuras públicas do país exerce sobre a formação Ética dos alunos e suas ações, já que estes acreditam no poder do "exemplo que vem de cima". Nas palavras de um aluno: "Como os mais poderosos já não agem corretamente, isto acaba influenciando o resto". No campo da Ética, o Brasil é percebido como "uma bagunça", constituindo-se em um ambiente de forte desestímulo ao comportamento ético. A insistência com que a mídia (frequentemente citada) vincula maus exemplos nesta área "mina a resistência intelectual que você tem para resistir aquilo". Uma ideia recorrente é a de que "se todo mundo faz, vou fazer também", como nos casos citados de se andar pelo acostamento para fugir do engarrafamento, comprar CD pirata, sonegar impostos, etc. Parece existir da parte de alguns alunos, uma sensação de prejuízo ou de logro ao se comportar eticamente em um ambiente onde os free-riders (SROUR, 2003) conseguem obter tantos benefícios (por conta de problemas sistêmicos no Brasil, tais como lentidão da justiça, impunidade, leis inadequadas à realidade). Neste contexto, grande parte dos participantes sente-se "autorizada" a se comportar de forma antiética. Estes reclamam da falta de Ética dos outros, mas acham que a sua é justificável, pois ocorre em consequência daquela. A indignação, neste caso, transforma-se em estímulo ao comportamento antiético, ao invés de provocar ações transformadoras desta realidade. Assim, a desordem Ética percebida no país, somada à impunidade, abre brechas e tolerância para o comportamento antiético, o "jeitinho" se 
impõe. Este discurso se coaduna com a visão antropológica de DaMatta (2000), para quem o jeitinho brasileiro é uma forma de navegação social, driblando adversidades sistêmicas da cultura brasileira, tais como impunidade, lentidão da justiça e da máquina governamental, desrespeito aos direitos básicos dos cidadãos, etc.

Em discordância à visão predominante, um aluno afirmou: "eu não penso assim: não interessa se o mundo é ou não ético, eu tento agir da melhor forma possível, eu acredito que se todo mundo que diz que hoje não tem como mudar o mundo, incentivar uma pessoa a agir corretamente...". Foi interrompido e duramente questionado por vários colegas, acusado de utópico: "isto funciona num mundo cor de rosa".

$\mathrm{O}$ agir ético aparece muitas vezes associado a estímulos externos (recompensas ou punições): uma aluna afirma que "é muito chato ser ético e não ser valorizado"; outros defendem que se acaba sendo mais ético na empresa, já que neste ambiente há mais controle do que no familiar, por exemplo. Mas a maioria defende que a "tendência espontânea" é ser mais ético com quem se gosta.

\section{Importância do estudo da Ética}

Ao abordarem a construção dos valores éticos das pessoas, os alunos não mencionaram espontaneamente a universidade como centro de formação. Como já foi dito, as instituições e ambientes ligados à infância ocupam lugar de destaque neste processo.

Quando estimulados a pensar sobre a formação Ética na universidade, manifestaram uma crença compartilhada e enfática na importância do estudo da Ética na faculdade, destacando que só uma disciplina não é suficiente, já que "não muda ninguém radicalmente", não pode transformar em pouco tempo o "caráter, a índole que ela [a pessoa] adquiriu ao longo da vida". Percebem uma utilidade relativa, já que a disciplina pode modificar alguns parâmetros éticos do aluno: "Mudar radicalmente não dá, mas mudar um ou outro parâmetro é possível"; "Depende se a pessoa está aberta ou não a ouvir outras pessoas"; "Com as discussões você pode mudar um pouco o seu ponto de vista, quem não é ético vai continuar assim, mas acho que vale a pena discutir". Esta visão é coerente com a visão de Wynd e Mager (1989) e de Bunke (1988), que enfatizaram as limitações do ensino da Ética como fator modificador da atitude dos alunos. 
Um aluno destacou o fato de que a disciplina de Ética fornece o "alento de ver que há outras pessoas [colegas, professor] que valorizam a Ética, em contraponto ao exemplo ruim presente na mídia”.

Um aluno, em opinião isolada, defendeu que a disciplina de Ética não teria nenhuma utilidade, já que Ética se aprende com a experiência de vida. Todos os outros discordaram, e o argumento preponderante foi de que as aulas também representam experiências importantes para a construção de valores éticos. $\mathrm{O}$ consenso dos grupos foi de que uma disciplina de Ética, por si só não consegue modificar a postura Ética dos alunos, mas pode contribuir para que este reflita sobre seus próprios valores e atitudes. Esta ideia corrobora a argumentação de Murphy e Boatright (1994), cujos estudos apontaram que o ensino da Ética contribui para que os alunos se tornem mais sensíveis a questões Éticas em sua vida profissional.

\section{Como deveria ser o ensino da Ética}

Nos alunos pesquisados pode-se perceber claramente a cobrança de que o tema Ética permeie o currículo da faculdade como um todo. Nas palavras dos alunos: "A Ética está em tudo, em todos os aspectos da vida"; "Está no conteúdo de todas as disciplinas, não deve ser ficar restrita a uma disciplina isolada"; "Administração tem a ver com dinheiro e pessoas, então tem tudo a ver com Ética, não é só uma disciplina"; "Ética é a base de tudo".

A maioria defendeu que todos os professores deveriam abordar questões Éticas associadas à sua disciplina, mas reconheceram que na prática isto não ocorre. Alguns alunos, de grupos diferentes, sugeriram que a faculdade promova palestras sobre o tema para os professores, para que estes possam se tornar multiplicadores.

Em relação ao ensino da Ética em uma disciplina específica, observam-se alguns consensos. $\mathrm{O}$ primeiro diz respeito à crença dos alunos na ineficácia da "pregação de valores" como metodologia de ensino. Ao contrário, a Ética deve ser abordada de maneira dinâmica, com métodos participativos, harmonizando-se com a visão defendida por Sims (2002), Brinkmann e Sims (2001), Sanyal (2000) e Burton, Johnston e Wilson (1991). Os alunos justificam a escolha destes métodos, afirmando que "são mais interessantes" e "envolvem mais a gente". O estudo de caso foi citado por um grande número de participantes como um método de ensino bastante adequado para este tema: "Você acha que aquilo pode acontecer mesmo e presta mais atenção"; "Se o professor não traz 
situações reais, por exemplo, um caso, a coisa parece muito abstrata e aí não tem muita graça não". Vale ressaltar que os alunos consideraram que os estudos de caso deveriam abordar não somente situações empresariais, mas também outras situações da vida cotidiana. Para eles, os valores éticos individuais não são acionados somente em uma situação específica, e a reflexão acerca do tema deve ser estimulada da forma mais ampla possível.

Houve consenso de que a provocação de debates sobre questões Éticas vinculadas ao dia-a-dia deve ser a tônica central de todas as aulas da disciplina. Múltiplas justificativas surgiram: "Quando você é levado a debater, isto te ajuda a formar opinião"; "Leva a questionamento das suas posições"; "Contribui para o autoconhecimento, pois coloca opiniões em xeque". A ideia central é de que, durante as discussões propostas em sala, os alunos ouvirão argumentos contrários à sua posição (em clima relativamente amigável e respeitoso) e poderão ser questionados pelos colegas, o que os levará a refletir posteriormente: "Algumas discussões mesmo que não façam você mudar de ideia na hora, te levam a ficar pensando, pensando"; "Talvez em uma discussão a pessoa vá negar, negar, negar, mas quando ela for pra casa vai ficar com aquilo na cabeça, vai ficar pensando". Com esta dinâmica, segundo eles, a pessoa "aprende a ouvir opiniões contrárias", "vai ficar mais aberta", "mais atenta". Ao promover reflexão sobre dilemas éticos associados à vida real, a aula oferece subsídios para posicionamento e tomada de decisão em situações do cotidiano: "às vezes você pode se encontrar em um dilema parecido lá na frente". Para a maioria dos participantes, há como levar os alunos a reflexões que poderão contribuir para que estes mudem ou reforcem seus valores, e isto poderá ter consequências positivas em sua atuação como gestores de organizações. As justificativas dadas pelos alunos alinham-se às ideias de Gautschi e Jones (1998) e Murphy e Boatright (1994), que reforçaram a importância do estudo da Ética como estímulo para a tomada de consciência dos alunos em relação a seus valores éticos.

Alguns alunos, embora reforçando a ideia da maioria de que discussões são fundamentais, ressaltaram o papel da teoria na disciplina de Ética: "Tem que ter teoria também, senão fica tudo muito solto"; "Um pouco de teoria é importante, porque forma uma base para a gente entender as situações e formar nossas opiniões"; "É preciso entender antes o conceito de Ética, para depois poder discutir".

Por fim, o papel do professor foi lembrado como fundamental na criação de um ambiente que propicie as discussões. "O professor tem que ser muito bem escolhido, não pode ser simplesmente alguém muito bom 
de Finanças ou de Marketing, precisa saber criar um ambiente mais solto para as discussões"; "O professor tem que ter habilidade, para que todo mundo se sinta à vontade de falar"; "Como é um assunto delicado, o professor tem que saber lidar com a turma". Conforme visto, a criação de um ambiente favorável às discussões e ao aparecimento de diferentes opiniões, bem como a importância do papel do professor foi ressaltada por Laditka e Houck (2006), Calloway-Graham (2004) e Sims (2002).

\section{Posicionamento da disciplina no curso}

Há um dissenso sobre o melhor momento para se colocar uma disciplina de Ética no curso de Administração. Os primeiros períodos são considerados inadequados, porque os alunos estão ainda se ambientando à faculdade, e são "muito imaturos". Os últimos períodos são também considerados inadequados pelo fato de a maioria dos alunos estarem envolvidos com trabalho e "muito atarefados". Outros defendem que o curso deve ser dado em períodos em que "os alunos estão estagiando e já têm uma noção melhor para relacionar o que se fala na aula com o mercado de trabalho".

Ao tentar definir qual o melhor momento do curso para a disciplina de Ética, percebe-se claramente, no discurso da maioria dos alunos, que estes consideram o tema como desconectado da atuação que têm/terão na vida profissional: "Ética não deve estar nos últimos períodos porque as matérias destes períodos deveriam estar focadas só no que o aluno realmente quer fazer"; "Nos últimos períodos as disciplinas devem ter a ver com a área em que o aluno quer atuar"; "Ética deveria ser uma matéria eletiva, só para aqueles que achassem que tem a ver".

Talvez esta falta de ligação da Ética com o mundo do trabalho seja oriunda do próprio programa do curso. Se os alunos percebem que no curso de Administração quase a totalidade das disciplinas não abordam questões relativas à Ética, tendem a dissociá-la de questões relacionadas à sua atuação profissional. É interessante notar que, mesmo afirmando a importância do estudo da Ética nos curso de Administração, os alunos, quando confrontados com a definição de quando inserir uma disciplina específica sobre o assunto, parecem não considerar que esta pode contribuir para sua formação como profissional. Neste momento, percebese uma visão instrumentalista dos alunos em relação à escolha do que aprender, negligenciando a Ética por esta não fazer parte do instrumental considerado como efetivamente útil para sua prática profissional. 


\section{CONSIDERAÇÕES FINAIS}

Este estudo visou aprofundar o conhecimento sobre opiniões e percepções de alunos de um curso de graduação em Administração de uma faculdade privada do Rio de Janeiro a respeito do ensino da Ética. Os resultados encontrados corroboram algumas recomendações da literatura e agregam novos caminhos para o ensino da Ética na faculdade de Administração.

Primeiramente, pode-se perceber uma consciência de que a formação Ética é um processo contínuo e acontece durante toda a vida, com influência de múltiplos ambientes e agentes sociais, com destaque para a família e a escola, no ensino fundamental.

É consensual a importância do ensino da Ética em cursos de Administração, mas há uma visão crítica em relação ao tratamento que a faculdade dá a este ensino, concentrando-o em uma única disciplina. Os alunos pesquisados defendem que este tema deveria ser abordado de alguma forma em todas as disciplinas do curso, já que a Ética permeia todos os aspectos da vida. Acreditam que a disciplina específica deve existir, mas seu poder transformador é limitado. Pode resultar na mudança de alguns parâmetros do aluno, mas dificilmente opera mudanças radicais de caráter. Sua principal contribuição é fazer com que o aluno reflita sobre seus próprios valores, ouvindo outras opiniões e aprendendo não só com o professor, mas também com a interação com seus colegas. Favorece, portanto, a tomada de consciência e aprimoramento dos valores éticos.

Como método de ensino, os alunos destacam o estudo de casos que abordem temas relativos à realidade empresarial e outros aspectos da vida cotidiana. Houve grande ênfase na importância dos debates como fio condutor do aprendizado, ressaltando-se o papel do professor na criação de um ambiente propício para que isto ocorra.

Por fim, expressando alguma contradição em relação à manifestada valorização do ensino da Ética, os alunos deixaram entrever uma visão instrumentalista em relação ao conteúdo do curso de Administração, priorizando disciplinas que consideram que contribuem mais diretamente para sua atuação profissional em detrimento da disciplina sobre Ética. Cabe aqui uma reflexão sobre a possibilidade de a mencionada visão estar sendo alimentada pela própria estrutura curricular dos cursos de Administração em geral, com abordagem compartimentada do ensino da Ética.

Os resultados deste estudo abrem um campo para temas de pesquisas futuras, entre os quais se destacam: avaliar e comparar as 
percepções e opiniões de outros alunos de MBA, de Mestrado, de instituições públicas e privadas - sobre o ensino da Ética; realizar estudo semelhante com alunos de outros cursos, para que se possa inferir possíveis semelhanças e diferenças em relação aos alunos de Administração; realizar estudo junto aos professores do curso de Administração sobre suas percepções a respeito do ensino da Ética, visando uma comparação com as percepções dos alunos.

\section{REFERÊNCIAS}

ADKINS, N.; RADTKE, R. Students' and Faculty Members Perceptions of the Importance of Business Ethics and Accounting Ethics Education: Is There an Expectations Gap? Journal of Business Ethics, v. 51, n.3, p. 279-300, 2004.

ALMEIDA, F. Ética e Desempenho Social das Organizaçőes: um Modelo Teórico de Análise dos Fatores Culturais e Contextuais. Revista de Administração Comtemporânea, v. 11, n. 3, p.105-125, 2007.

ARLOW, P.; ULRICH, T. A Longitudinal Survey of Business School Graduates' Assessments of Business Ethics. Journal of Business Ethics, v. 7, n. 4, p. 295-302, 1988.

ARRUDA, M.C.C DE; WHITAKER, M.C.; RAMOS, J.M.R. . Fundamentos de Ética Empresarial e Econômica. 3.ed. São Paulo: Atlas, 2005.

ASHLEY, P.; QUEIROZ, A.; CARDOSO, A.; SOUZA, A.; TEODÓSIO, A.; BORINELLE, B.; VENTURA, E.; CHAVES, J.; VELOSO, L.; ALIGLERI, L.; LIMA, P.; FERREIRA, R. Ética e Responsabilidade Social nos Negócios. 2.ed. São Paulo: Saraiva, 2005.

BARBOSA, L. Igualdade e Meritocracia: a Ética do Desempenho nas Sociedades Modernas. Rio de Janeiro: FGV, 1999.

BARROS, M.; PASSOS, E. . Remando a Favor da Maré: Racionalidade Instrumental no Curso de Administração de Empresas. Organização \& Sociedade, v.7, n. 19, p. 161-174, 2000.

BORGER, F. Responsabilidade Social: Efeitos da Atuação Social na Dinâmica Empresarial. São Paulo, 2001. Tese (Doutorado em Administração) - Faculdade de Economia, Universidade de São Paulo.

BOYD, T. Improving Ethical Awareness Through the Business and Society Course. Business and Society, v. 20, n. 1, p. 27-31, 1981. 
BRINKMANN, J.; SIMS, R. Stakeholder-Sensitive Business Ethics Teaching. Teaching Business Ethics, v. 5, n.2, p.171-193, 2001.

BUNKE, H. Should We Teach Business Ethics? Business Horizons, v. 31, n.4, p. 2-8, 1988.

BURTON, S; JOHNSTON, M.; WILSON, E. An Experimental Assessment of Alternative Teaching Approaches for Introducing Business Ethics to Undergraduate Students. Journal of Business Ethics, v. 10, n. 7, p. 507-517, 1991.

CALLOWAY-GRAHAM, D. The art of teaching and learning. The Social Science Journal, v. 41, n. 4, .p. 689-694, 2004.

CAMPOS, T. Políticas para Stakeholders: um Objetivo ou uma Estratégia Organizacional? Revista de Administração Contemporânea, v. 10, n.4, p.111-130, 2006.

CARROL, A. Corporate Social Responsibility Evolution of a Definitional Construct. Business \& Society, v. 38, n.3, p.268-295, 1999.

CHERMAN, A.; TOMEI, P. Códigos de Ética Corporativa e a Tomada de Decisão Ética: Instrumentos de Gestão e Orientação de Valores Organizacionais? Revista de Administração Contemporânea, v. 9, n. 6, p. 75-95, 2005.

COLE, B.; SMITH, D. Effects of Ethics Instruction on the Ethical Perceptions of College Business Students. Journal of Education for Business, v. 70, n. 6, p. 351-355, 1995.

DAMATTA, R. O que faz o Brasil, Brasil? Rio de Janeiro: Rocco, 2000.

DUIZEND, J.; MCCANN, G. Do Collegiate Business Students Show a Propensity to Engage in Illegal Business Practices? Journal of Business Ethics, v. 17, n. 3, p. 229-238, 1998.

ERFFMEYER, R.; KELLOR, B.; LECLAIR, D. An Empirical Investigation of Japanese Consumer Ethics. Journal of Business Ethics, v. 18, n. 1, p.35-50, 1999.

FARIA, M.; CARVALHO, J. A falta de Ética como consequência da hipertrofia da racionalidade instrumental nas ações de responsabilidade social corporativa. In: XXVIII Encontro Nacional de Engenharia de Produção - Enegep, 2008, Rio de Janeiro. Anais... Rio de Janeiro: Abepro, 2008. 
FELLDMAN, H.; THOMPSON, R. Teaching Business Ethics: a Challenge for Business Educators in the 1990s. Journal of Marketing Education, v.2, p. 123-145, 1990.

FELTON; SIMS. Teaching Business Ethics: Target Outputs. Journal of Business Ethics, v. 60, n. 4, p.377-391, 2005.

FERRELL, O. FRAEDRICH, J.; FERRELL, L. Ética Empresarial: dilemas, tomadas de decisões e casos. Tradução Cecília Arruda. Rio de Janeiro: Reichmann \& Affonso Ed., 2001.

GATTI, B. Grupo Focal na Pesquisa em Ciências Sociais e Humanas. Brasília: Líber Livros, 2005.

GAUTSCHI III, F.; JONES, T. Enhancing the Ability of Business Students to Recognize Ethical Issues: An Empirical Assessment of the Effectiveness of a Course in Business Ethics. Journal of Business Ethics, v. 17, n. 2, p. 205-216, 1998.

GAVA, R.; SILVEIRA, T. A orientação para o mercado sob a ótica da empresa e dos clientes na indústria hoteleira gaúcha. Revista de Administração Contemporânea, v.11, n. 2, p. 49-69, 2007.

ICHIKAWA, E. Formação Profissional e Ética no Curso de Administração: Leitura de Estudantes de Graduação em Uma Faculdade Particular. In: XXX Encontro Nacional da Associação Nacional de PósGraduação e Pesquisa em Administração - EnANPAD, 2006, Salvador. Anais... Salvador: Anpad, 2006.

INSTITUTO ETHOS. Responsabilidade Social das Empresas Percepção do Consumidor Brasileiro. Disponível em:

http://www1.ethos.org.br/EthosWeb/Default.aspx. Acesso em: 10/01/2011.

KRUEGER, R. Focus Groups: The Practical Guide goes Applied Research. 3.ed. Thousand Oaks: SAGE Publications, 2000.

LADITKA, S.; HOUCK, M. Student-Developed Case Studies: An Experiential Approach for Teaching Ethics in Management. Journal of Business Ethics. v. 64, n. 2, p. 157-167, 2006.

MACFARLANE, B. Business and management studies in higher education: the challenge of academic legitimacy. International Journal of Educational Management, v. 9, n.5, p. 4-9, 1995. 
MARTIN, T. Do Courses in Ethics Improve the Ethical Judgment of Students? Business and Society, v. 20, n. 1, p.13-21, 1981.

MCDONALD, G.; ONLEAVY, G. Objectives to the Teaching of Business Ethics. Journal of Business Ethics, v. 10, n. 1, p. 829-835, 1995.

MINAYO, M. O desafio do conhecimento: pesquisa qualitativa em saúde. 8.ed. São Paulo: Hucitec, 2004.

MOHR, L.; WEBB, D.; HARRIS, K. Do Consumers Expect Companies to be Socially Responsible? The Impact of Corporate Social Responsibility on Buying Behavior. The Journal of Consumer Affairs, v. 35, n.1, p.45-72, 2001.

MORGAN, D. Successful Focus Groups: Advancing The State Of The Art. Thousand Oaks: Sage Publications, 1993.

MURPHY, P.; BOATRIGHT, J. Assessing the Effectiveness of Instruction in Business Ethics: A Longitudinal Analysis. Journal of Education for Business, v. 69, n. 6, p. 326-332, 1994.

PASSOS, E. Ética nas Organizações. São Paulo: Atlas, 2004.

SANYAL, R. An Experiential Approach to Teaching Ethics in International Business. Teaching Business Ethics, v. 4, n. 1, p.137-149, 2004.

SCHWARTZ, R.; KASSEM, S.; LUDWIG, D. The Role of Business Schools in Managing the Incongruence Between What is Right and Doing What it Takes to Get Ahead. Journal of Business Ethics, v. 10, n.6, p. 465-469, 1991.

SERPA, D. Ética e Responsabilidade Social Corporativa são Realmente Importantes? Um Estudo com Futuros e Atuais Gestores de Empresas. In: In: XXIX Encontro Nacional da Associação Nacional de Pós-Graduação e Pesquisa em Administração - EnANPAD, 2005, Brasília. Anais... Brasília: Anpad, 2005.

SERPA, D.; FOURNEAU, L. O Consumidor Ético Brasileiro: Realidade ou Ficção? In: XVII Congresso Latino-Americano de Estratégia, 2004, Florianópolis. Anais... Florianópolis: 2004.

SIMS, R. Business Ethics Teaching for Effective Learning. Teaching Business Ethics, v. 6, n.4, p. 393-410, 2002. 
SIMS, R.; SIMS, S. Increasing Applied Business Ethics Courses in Business School Curricula. Journal of Business Ethics, v. 10, n.3, p. 211219, 1991.

SMITH, D. Ethical Reflection and Service Internships. Journal of Business Ethics, v. 15, n.1, p. 59-65, 1996.

SROUR, R. Ética Empresarial: posturas responsáveis nos negócios, na política e nas relações pessoais. Rio de Janeiro: Campus, 2003.

STEAD, B.; MILLER, J. Can Social Awareness Be Increased Through Business School Curricula? Journal of Business Ethics, v. 7, n. 7, p. 553$560,1988$.

THOMPSON, C. J. Interpreting consumers: a hermeneutical framework for deriving marketing insights from the texts of consumers' consumption stories. Journal of Marketing Research, v. 34, n. 4, p. 438-455, 1997.

VALLS, A. O Que é Ética. São Paulo: Brasiliense, 1994.

VERGARA, S. Projetos e relatórios de pesquisa em Administração. 10.ed. São Paulo: Atlas, 2009.

WEBER, J. Measuring the Impact of Teaching Ethics to Future Management: A Review Assessment, and Recommendations. Journal of Business Ethics, v. 9, n. 3, p.23-44, 1990.

WYND, W.; MAGER, J. The Business and Society Course: Does It Change Student Attitudes? Journal of Business Ethics, v. 8, n. 6, p. 487491, 1989. 


\section{DADOS DOS AUTORES}

DANiela Abrantes FerReira (dabrantes@uol.com.br)

Doutora em Administração pela COPPEAD/UFRJ

Instituição de vinculação: Universidade Federal do Rio de Janeiro

Rio de Janeiro/RJ - Brasil

Áreas de interesse em pesquisa: Comportamento do Consumidor; Ética e Responsabilidade Social.

LUCELENA FERREIRA (lucelena@ terra.com.br)

Doutora em Pedagogia pela PUC/Rio

Instituição de vinculação: Ibmec-Rio de Janeiro

Rio de Janeiro/RJ - Brasil

Áreas de interesse em pesquisa: Ética e Responsabilidade Social.

MARINA DIAS DE FARIA (marinafaria86@ hotmail.com)

Mestre em Administração pela PUC-Rio

Instituição de vinculação: Universidade Federal do Rio de Janeiro

Rio de Janeiro/RJ - Brasil

Áreas de interesse em pesquisa: Comportamento do Consumidor.

Recebido em: 05/03/2010 • Aprovado em: 28/01/2011 